\title{
The Equity Research Program's Effect on Technology Investors: The Tel-Aviv Stock Exchange Case Study
}

\author{
Tiran Rothman \\ School of Management, Wizo Academic College, Haifa, Israel \\ Frost \& Sullivan \\ Chen Yakar \\ IDC Herzliya - Arison School of Business, Herzliya, Israel \\ Frost \& Sullivan
}

Doi:10.19044/esj.2019.v15n7p121～ＵRL:http://dx.doi.org/10.19044/esj.2019.v15n7p121

\begin{abstract}
The Tel-Aviv Stock Exchange (TASE) initiated an equity research program in 2016 dedicated to the technology sector. The main goal of the program was to draw more investor attention to Israeli tech firms. Today, nearly all equity research is performed by stock brokers, investment banks, and other entities which have a financial interest in the market. On the other hand, independent equity research is a boutique service offered by only a few firms worldwide. The aim of such research is to provide an unbiased opinion on the state of a company, including its share price and potential forthcoming changes. We conducted a study to explore events, such as initiation analysis report publications, as the release of new information to market participants. We hope to contribute to the growing literature on the effect of analyst reports on investor activities. Our findings indicate a broad market reaction to equity research reports published in TASE during 2017-2018.
\end{abstract}

Keywords: Attention, inefficient market; Corporate News; Event Study; Equity research; Financial Markets.

\section{Introduction}

In 2016, TASE initiated an equity research program dedicated to the technology sector. The main goal of the program was to draw more investor attention to Israeli tech firms. This research was led by two firms: Edison (www.edisonequityresearch.com) and the consultancy and global research firm, Frost \& Sullivan (www.frost.com).

Nearly all equity research is nowadays performed by stock brokers, investment banks, and other entities which have a financial interest in the market. On the other hand, independent equity research is a boutique service 
offered by only a few firms worldwide. The aim of such research is to provide an unbiased opinion on the state of a company, including its share price and potential forthcoming changes. The analysis does not constitute investment advice, and analysts are prohibited from trading any securities being analyzed. Furthermore, companies (like Frost \& Sullivan) that offer these services are contracted by a third party entity, such as TASE, and not the company directly. Compensation is received up front to further secure independent coverage.

Within the framework of TASE's ongoing program, Edison and Frost \& Sullivan produce equity research reports on technology and biomedical companies that are listed on TASE. The firms also disseminate these reports online via message boards and leading business media channels. The goals of the program are to enhance global awareness of these companies in focus, and to encourage more informed investment decisions. Terms of the program are governed by TASE and by the Israeli Securities Agency (ISA).

\section{Literature overview}

Sell-side analysis has existed for years. However, the difference between sell-side and equity research lies in the interests of the analysts. Sell-side analysts often do not charge fees from the firms, but offer the firms other services, such as underwriting for their future capital raising. On the other hand, equity research firms charge a fixed fee, unrelated to the research outcome. The latter approach results in a less biased analysis.

The value of sell-side equity research is a source of ongoing debate among academics, investment professionals, regulators, and the financial media. On the one hand, studies consistently demonstrate that earnings forecasts, target prices, investment recommendations, and narrative commentaries contain information for investors (Womack 1996; Givoly and Lakonishok 1979; Lys and Sohn 1990; Brav and Lehavy 2003; Asquith et al. 2005; Call, Chen, Tong 2013 and Min 2016). Nevertheless, a large body of evidence suggests that the social context in which analysts operate renders their research biased, incomplete, excessively dependent on management, reliant on the past repeating itself, and lacking in scientific method (Abarbenall and Bernard, 1992; Fogarty and Rogers, 2005; Kothari et al., 2009). Fogarty and Rogers (2005) conjecture that rather than reflecting a neutral and stable expertise that is unaffected by social context, analysts' work is more accurately characterized by an institutionalized structure where their independence is compromised by financial conflicts of interest and excessive reliance on management as a source of firm-specific information, and where as a consequence, symbolic displays substitute rigorous scientific analysis. Consistent with institutional theory, Fogarty and Rogers (2005) find that analyst research is uncritical of management and naïve in the view that past outcomes hold the clues to predicting the future. Asquith et al. (2005) and 
Huang et al. (2012) confirm that the average analyst report contains little negative commentary about firms or management. Further, Kothari et al. (2009) find no significant association between the content of analyst research and firms ' cost of capital, which they attribute to credibility and timeliness problems with sell-side research. Collectively, these findings echo doubts expressed by the media, investment professionals, and regulators over the rigor and objectivity of analysts' work, supported by insights from psychology that stress the conditional nature of individuals' attributional search processes (e.g., Lau and Russell, 1980).

Despite robust evidence for the conditional nature of attributional search, studies examining the properties of analyst commentaries typically adopt a random sampling approach designed to maximize generalizability (e.g., Asquith et al., 2005; Fogarty and Rogers, 2005). However, since a high fraction of analyst research is released in response to either good news or existing information (e.g., Asquith et al., 2005), failure to account for the incentives for attributional search can tilt the evidence in favor of observing bland, management-friendly research that lacks scientific rigor. Examples include: Financial Times, "Shoot All the Analysts”, March 20, 2001, page 22; Wall Street Journal, "Outlook for Analysts: Skepticism and Blame”, June 13, 2001; Financial Times, "Titans who were brought to book", March 11, 2008; Financial Times, "Investment research fights to prove its worth", March 19, 2009; Financial Times, "Sell-side research hit by quality controls", June 19, 2009.

\section{Research method}

This paper uses an event-study approach (ESA), which is an effective tool for assessing the information content of events, as perceived by market participants, as well as shedding light on the issue of market efficiency or inefficiency (Campbell et al. 2012). The underlying idea in common event studies is to track the market prices of securities whose issuing firms were involved in the studied event, in order to detect market-related reactions. The prices are tracked over a period that is potentially relevant for evaluating the effect of the event on the prices of the traded securities; this period is termed the event window (cf. Kliger and Gurevich, 2014, chapter 3).

Commonly, the market reaction to the studied events has an intuitively predictable direction. That is, in events consisting of good news, the market participants are expected to react positively, thereby raising the security prices of the firms undergoing the studied event. Conversely, in bad-news events, the market participants are expected to react negatively, and the security prices are expected to fall.

In our event-study model, we present the estimated cumulative average abnormal return (CAAR) over a period of time $t$ to $t+x$, and the estimated 
average abnormal return (AAR) at time t. The CAAR is calculated based on a basic naïve benchmark model assuming the normal return for all stocks to be the market return as represented by a broad stock market index, such as the S\&P 500 and the healthcare index representing the whole pharmaceutical industry. In effect, the naïve benchmark regards anything different from the average market behavior as abnormal. It is termed naïve because it ignores basic economic assumptions, such as allowing riskier stocks to command higher expected returns due to investors' risk aversion. This single-factor benchmark assumes linear relations between stock and market-index returns, and includes the parameters $\alpha_{i}$ and $\beta_{i}$, which are usually estimated by a linear regression with the stock return as the response variable and the market return as the predictor variable. To obtain estimates that are not affected by the studied event, the data range for the regression must be chosen in a way that minimizes the possible influence of the event; that is, the range should not belong to the event window. The rationale for this range is to estimate parameters that are representative of the stock but are unaffected by the event, so they enable estimation of the "normal" stock return, which in turn enables detecting irregularities or "abnormal" returns.

\section{Testable hypotheses for the equity research program effect}

Hypothesis 1, pre equity research (ER) publication: Pre-event attention: upcoming ER publication ignites a period of investor attention to the stocks covered in the program, thereby causing: (i) an upward trend in cumulative abnormal returns and (ii) increased trading activity, manifested by positive abnormal trading volume.

Hypothesis 2, post ER publication: Post-event attention: in the period following ER publication, we observe a decrease in investor attention to the stocks covered in the program, thereby causing: (i) a downward trend in cumulative abnormal returns and (ii) decreased trading activity, manifested by positive abnormal trading volume. 


\section{Data and analysis}

\subsection{Data}

The data consist of all 20 firms entered into the equity research analysis program with TASE as shown in table 1 below:

Table 1: List of 20 traded TASE firms participating in the equity research program and date of initiation report:

\begin{tabular}{ccc}
\hline No & Company & Date of Initiation Report \\
\hline $\mathbf{1}$ & Allium Medical Solutions (ALMD) & $11 / 2 / 16$ \\
$\mathbf{2}$ & BioLight Life Sciences (BOLT) & $19 / 10 / 16$ \\
$\mathbf{3}$ & Clal Biotechnology Industries (CBI) & $15 / 1 / 18$ \\
$\mathbf{4}$ & CollPlant Holdings (CLGN) & $3 / 9 / 17$ \\
$\mathbf{5}$ & Ellomay Capital (ELLO) & $28 / 9 / 16$ \\
$\mathbf{6}$ & Foresight Autonomous Holdings (FRST) & $27 / 9 / 16$ \\
$\mathbf{7}$ & Intec Pharma (NTEC) & $29 / 09 / 16$ \\
$\mathbf{8}$ & Nano Dimension (NNDM) & $9 / 12 / 16$ \\
$\mathbf{9}$ & Pluristem Therapeutics (PSTI) & $23 / 11 / 16$ \\
$\mathbf{1 0}$ & Pointer Telecom (PNTR) & $11 / 8 / 16$ \\
$\mathbf{1 1}$ & BiolineRX Ltd. (BLRX) & $20 / 7 / 17$ \\
$\mathbf{1 2}$ & Brainsway Ltd. (BRIN) & $6 / 8 / 17$ \\
$\mathbf{1 3}$ & D.N.A. Biomedical Solutions (DNA) & $10 / 10 / 17$ \\
$\mathbf{1 4}$ & Oramed Pharmaceuticals Inc. (ORMD) & $23 / 12 / 17$ \\
$\mathbf{1 5}$ & Redhill Biopharma Ltd. (RDHL) & $12 / 7 / 17$ \\
$\mathbf{1 6}$ & Energix Renewable Energies Ltd. (ENRG) & $25 / 6 / 17$ \\
$\mathbf{1 7}$ & Enlight Renewable Energy Ltd. (ENLT) & $28 / 1 / 18$ \\
\hline $\mathbf{1 8}$ & Safe-T Group Ltd. (SAFT) & $2 / 7 / 18$ \\
\hline $\mathbf{1 9}$ & Vonetize PLC (VNTZ) & $2 / 10 / 17$ \\
\hline
\end{tabular}

We gathered all prices and volume data from www.tase.co.il. All sector data was also extracted from the same website.

\subsection{Analysis}

Table 1 plots CAARs around initiation report publication. At the prepublication period there is no market reaction. On the day of publication CAAR is $1.97 \%$ (t-stat, 2.20) and ten trading days post publication we see a robust and significant effect of the initiation analysis report at $6.44 \%$ (t-stat, 2.39). We see a downward effect after 30 days post initiation report publication. 
Table 2: CAARs and abnormal daily price statistics around initiation analysis report publication, for $\mathbf{- 5 0}$ to $+\mathbf{5 0}$ days

\begin{tabular}{|c|c|c|}
\hline \multirow{2}{*}{\begin{tabular}{l}
\multicolumn{1}{c}{ Days } \\
relative \\
event
\end{tabular}} & \multicolumn{2}{|c|}{ Equity research firms } \\
\hline & CAAR, \% & t-statistic \\
\hline-50 to -1 & $0.41 \%$ & 0.06 \\
\hline-40 to 1 & $-0.59 \%$ & -0.10 \\
\hline-30 to 1 & $-1.88 \%$ & -0.38 \\
\hline-10 to 1 & $-0.58 \%$ & -0.20 \\
\hline-2 & $0.31 \%$ & 0.34 \\
\hline-1 & $-0.68 \%$ & -0.75 \\
\hline 0 & $1.97 \%$ & 2.20 \\
\hline 1 & $1.17 \%$ & 1.31 \\
\hline 2 & $0.51 \%$ & 0.57 \\
\hline 3 & $0.24 \%$ & 0.27 \\
\hline 0 to 10 & $6.44 \%$ & 2.39 \\
\hline 0 to 20 & $4.77 \%$ & 1.22 \\
\hline 2 to 30 & $0.16 \%$ & 0.03 \\
\hline 2 to 40 & $-5.53 \%$ & -0.99 \\
\hline 2 to 50 & $-5.10 \%$ & -0.81 \\
\hline
\end{tabular}

Figure 1: CAARs and abnormal daily volume statistics around initiation analysis report publication, for -50 to +50 days

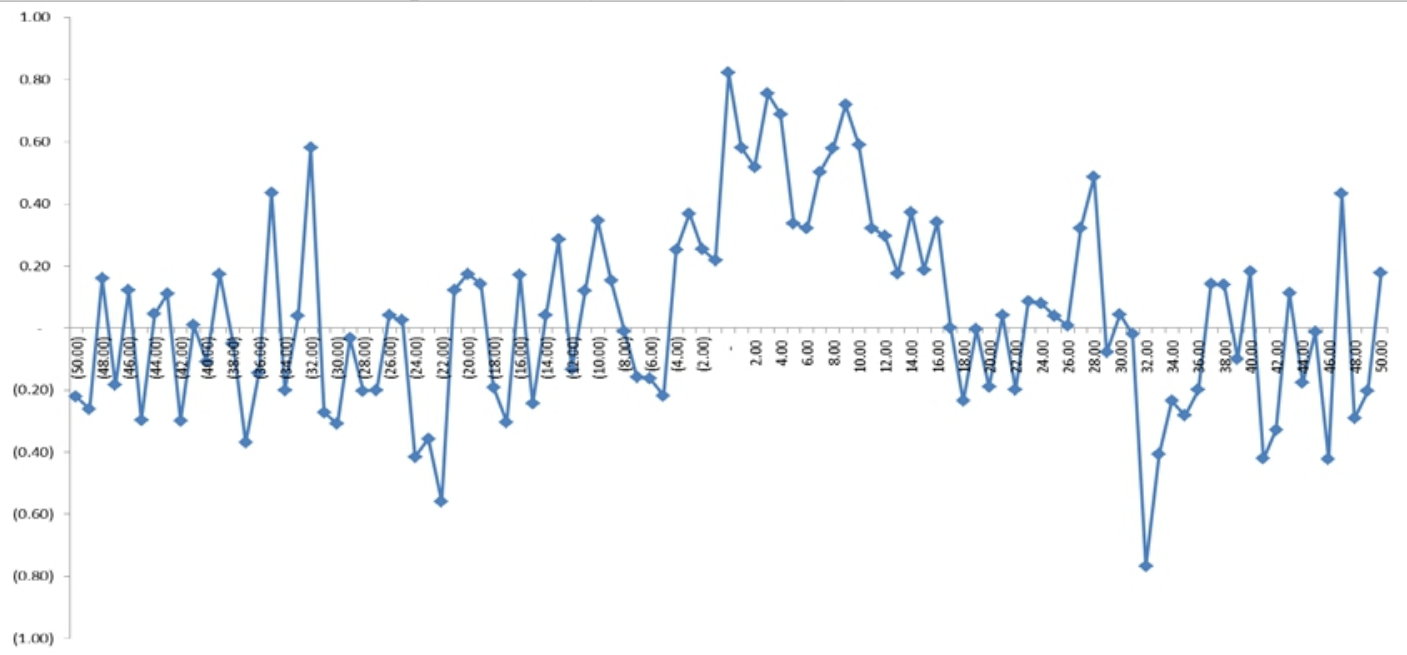


Table 3: CAARs and abnormal daily volume statistics around initiation analysis report publication, for +20 days versus market sector (TASE technology sector)

\begin{tabular}{|rlrrrr|}
\hline \multicolumn{1}{c}{$\mathbf{N o}^{\prime}$} & \multicolumn{1}{c}{ Company } & Date of Initiation Report & Companies & Sector & Delta \\
\cline { 2 - 5 } 1 & Allium Medical Solutions (ALMD) & $11 / 2 / 16$ & $-37 \%$ & $-20 \%$ & $-17 \%$ \\
2 & BioLight Life Sciences (BOLT) & $19 / 10 / 16$ & $4 \%$ & $79 \%$ & $-75 \%$ \\
3 & Clal Biotechnology Industries (CBI) & $15 / 1 / 18$ & $-27 \%$ & $-27 \%$ & $0 \%$ \\
4 & CollPlant Holdings (CLGN) & $3 / 9 / 17$ & $-21 \%$ & $14 \%$ & $-36 \%$ \\
5 & Ellomay Capital (ELLO) & $28 / 9 / 16$ & $58 \%$ & $45 \%$ & $13 \%$ \\
6 & Foresight Autonomous Holdings (FRST) & $27 / 9 / 16$ & $215 \%$ & $44 \%$ & $171 \%$ \\
7 & Intec Pharma (NTEC) & $29 / 09 / 16$ & $48 \%$ & $47 \%$ & $2 \%$ \\
8 & Nano Dimension (NNDM) & $9 / 12 / 16$ & $128 \%$ & $37 \%$ & $91 \%$ \\
9 & Pluristem Therapeutics (PSTI) & $23 / 11 / 16$ & $105 \%$ & $37 \%$ & $68 \%$ \\
10 & Pointer Telocation (PNTR) & $11 / 8 / 16$ & $398 \%$ & $16 \%$ & $382 \%$ \\
11 & BiolineRX Ltd. & $20 / 7 / 17$ & $5 \%$ & $4 \%$ & $0 \%$ \\
12 & Brainsway Ltd. & $6 / 8 / 17$ & $-47 \%$ & $11 \%$ & $-58 \%$ \\
13 & D.N.A. Biomedical Solutions & $10 / 10 / 17$ & $2 \%$ & $7 \%$ & $-4 \%$ \\
14 & Oramed Pharmaceuticals Inc. & $23 / 12 / 17$ & $-48 \%$ & $-21 \%$ & $-27 \%$ \\
15 & Redhill Biopharma Ltd. & $12 / 7 / 17$ & $28 \%$ & $-5 \%$ & $33 \%$ \\
16 & Energix Renewable Energies Ltd. & $25 / 6 / 17$ & $7 \%$ & $-13 \%$ & $20 \%$ \\
17 & Enlight Renewable Energy Ltd. & $28 / 1 / 18$ & $76 \%$ & $14 \%$ & $62 \%$ \\
18 & Safe-T Group Ltd. & $2 / 7 / 18$ & $226 \%$ & $-13 \%$ & $239 \%$ \\
19 & Vonetize PLC & $2 / 10 / 17$ & $-75 \%$ & $14 \%$ & $-88 \%$ \\
20 & Kadimastem & $12 / 6 / 18$ & $36 \%$ & $-9 \%$ & $45 \%$ \\
Total average volume change & & $\mathbf{5 4 \%}$ & $\mathbf{1 3 \%}$ & $\mathbf{4 1 \%}$ \\
\hline
\end{tabular}

\section{Discussion and conclusion}

Our findings indicate a broad market reaction to equity research analysis reports published in TASE during 2017-2018. These findings support other studies (e.g., Asquith et al., 2005) showing that a high fraction of analyst research is released in response to either good news or no material new information. We find that although the market anticipates and is aware of future publication, we still witness a robust market reaction. We postulate that this market reaction is due to the nature of the firms under scrutiny, as all these firms are small-cap firms (under \$5bn market cap); thus, they can be viewed as 'under-the-radar' firms. Namely, new information provided in equity research reports creates new hype, thus we see share price as well as volume increase.

\section{References:}

1. Abarbanell, J. S., \& Bernard, V. L. (1992). Tests of analysts' overreaction/underreaction to earnings information as an explanation for anomalous stock price behavior. The Journal of Finance, 47(3), 1181-1207.

2. Asquith, P., Mikhail, M. B., \& Au, A. S. (2005). Information content of equity analyst reports. Journal of financial economics, 75(2), 245282. 
3. Brav, A., \& Lehavy, R. (2003). An empirical analysis of analysts' target prices: Short-term informativeness and long-term dynamics. The Journal of Finance, 58(5), 1933-1967.

4. Call, A. C., Chen, S., \& Tong, Y. H. (2013). Are analysts' cash flow forecasts naïve extensions of their own earnings forecasts?. Contemporary Accounting Research, 30(2), 438-465.

5. Fogarty, T. J., \& Rogers, R. K. (2005). Financial analysts' reports: an extended institutional theory evaluation. Accounting, Organizations and Society, 30(4), 331-356.

6. Givoly, D., \& Lakonishok, J. (1979). The information content of financial analysts' forecasts of earnings: Some evidence on semistrong inefficiency. Journal of Accounting and Economics, 1(3), 165185.

7. Kliger, D., \& Gurevich, G., 2014, Hands-On Guide to Event Studies for Financial Research, Palgrave-Macmillan

8. Lys, T., \& Sohn, S. (1990). The association between revisions of financial analysts' earnings forecasts and security-price changes. Journal of Accounting and Economics, 13(4), 341-363.

9. Min, C. (2016). A Study On Corporate Governance And Performance Effect Of Institutional Investors. European Scientific Journal, ESJ, 12(16), 363.

10. Neuhierl, A., Scherbina, A., \& Schlusche, B., 2010, Market Reaction to Corporate Press Releases, working paper.

11. Rothman, T. (2017). Investors' Cognitive Mechanisms within the Drug Development Industry. American Scientific Research Journal for Engineering, Technology, and Sciences 33(1), 196-206.

12. Womack, K. L. 1996. Do brokerage analysts' recommendations have investment value? Journal of Finance 51: 137-167. 